\title{
Microstructural studies of ultrarapidly quenched foils of zinc-doped indium-tin eutectic alloys
}

\author{
Vasiliy G. Shepelevich ${ }^{1}$, Olga V. Gusakova ${ }^{2}$, Elena L. Koukharenko ${ }^{3, *}$ (D), and Sofia V. Husakova ${ }^{1}$ \\ ${ }^{1}$ Department of Solid State Physics, Belarusian State University, Nezavisimosti Ave, 4, 220030 Minsk, Belarus \\ ${ }^{2}$ Department of Nuclear and Radiation Safety, International Sakharov Environmental Institute of Belarusian State University, \\ Dolgobrodskaya St., 23/1, 220070 Minsk, Belarus \\ ${ }^{3}$ Electronics and Computer Science, University of Southampton, Highfield, Southampton SO17 1BJ, UK
}

Received: 16 June 2018

Accepted: 24 September 2018

Published online:

8 October 2018

(C) The Author(s) 2018

\begin{abstract}
Alloys with the composition of Sn (46.5 at.\%)-In (50.7 at.\%)-Zn (2.8 at.\%) were fabricated by using the ultrarapid quenching process, with quenching rate up to $10^{5} \mathrm{~K} / \mathrm{s}$. These materials were obtained in the shape of foils with a thickness varying from 30 to $70 \mu \mathrm{m}$. Their phase composition, microstructure, grain structure, and texture have been analyzed and revealed that these alloys consist of solid solutions based on the $\beta$ phase $\left(\mathrm{In}_{3} \mathrm{Sn}\right)$ and $\gamma$ phase $\left(\mathrm{InSn}_{4}\right)$ with inclusions of zinc. Aging processes in the foils revealed that the volume fraction of zinc $\left(\mathrm{V}_{\mathrm{Zn}}\right)$ increases with the increase in the samples exposure time to the air at room temperature. The electron backscatter diffraction analysis has shown that these foils have a microcrystalline structure. The mechanism of the texture formation in these materials has been explained.
\end{abstract}

\section{Introduction}

The most popular soldering materials used in electronic packaging are the eutectic $\mathrm{Sn}-37 \mathrm{~Pb}$ and near eutectic $\mathrm{Sn}-\mathrm{Pb}$. However, recent environmental concerns and the increasing awareness of health risk associated with lead-containing solder alloys have pushed the electronics industry toward lead-free compositions, leading to environmental concerns over the amount of lead ending up in landfill [1,2].

In Europe, the waste electrical and electronic equipment (WEEE) directive by EU has banned the use of $\mathrm{Pb}$ in consumer goods, while the restriction of hazardous substances (ROHS) compliance has claimed that $\mathrm{Pb}$ is the most common material that must be eliminated [3].

Hence, in recent years, there has been a significant amount of efforts dedicated by the research community and its related industrial users to investigate $\mathrm{Pb}$-free eco-friendly solders alternatives suitable for a wide range of applications [4, 5]. To this end, new types of solders are being currently developed by using complex multicomponent alloys, time-consuming, costly or sophisticated fabrication techniques requiring a careful approach to melting, using noble metals or rare earths ( $\mathrm{Au}, \mathrm{Ag}, \mathrm{RE})$. Several groups focused their research on $\mathrm{Sn}-\mathrm{Ag}$-based alloys. Chen et al. [6] investigated the $\mathrm{SnAgCu}-\mathrm{RE}$ alloy

Address correspondence to E-mail: ak@ecs.soton.ac.uk 
manufactured by multiple steps of melting and using one of the rarest elements. Li et al. developed $\mathrm{Sn}-\mathrm{Bi}-$ In alloys by multiple re-melting steps [7] as it has been difficult to obtain homogeneous mixture required for good quality solders. Hindler et al. [8] investigated the thermodynamics of Au-based alloys, including $\mathrm{Au}-\mathrm{Sb}-\mathrm{Sn}$ and $\mathrm{Au}-\mathrm{Sb}$, by using conventional quenching in iced water, a time-consuming process.

In general, while there are many research publications about high-temperature solders, like $\mathrm{Sn}-\mathrm{Ag}-$ $\mathrm{Cu}$, there is very limited amount of research reported in literature that is dedicated to solders with melting temperature around $110{ }^{\circ} \mathrm{C}[6]$.

Very recently, Maruya et al. [9] investigated samples combining $\mathrm{Sn}-\mathrm{Bi}-\mathrm{Ag}$ alloys and gold fabricated by electroplating that are expected to be a good candidate for low-temperature lead-free soldering. However, this approach has shown several drawbacks, such as being time-consuming and requiring sophisticated processing, as it involves multiple fabrication steps at different temperatures ramping. Besides, current low melting temperature solders face several key challenges, which include more intermetallic compound formation (thus becoming more brittle), high cost associated with the addition of supplementary elements to decrease the melting point temperature, and an increase in the possibility of thermal or popcorn cracking (reliability problems) [9].

Thus, the pursuit of more advanced low melting temperature solders for interconnections is timely. The motivation of this research is to develop highperformance and environmentally friendly solders, fabricated by easy and low-cost fabrication processes. The focus of this research is $\mathrm{Zn}$-doped indium-tin eutectic alloys.

The fabrication of solders with low melting point of about $120{ }^{\circ} \mathrm{C}$ is possible by using the eutectic system of indium-tin [10]. In such low melting point solders, plastic deformation is possible at operating temperatures that occurs according to the mechanism of the grain-boundary slip, which is manifested in creep processes [11]. Therefore, in order to reduce the effect of grain-boundary slippage, various components are added to the eutectic, such as zinc, bismuth and antimony [12]. Since zinc has a limited solubility in tin and indium, its inclusions can be formed in the alloy at the boundaries of the phases forming the eutectic, which effectively prevent grain-boundary slippage.

At low and medium cooling rates of the melt, dendritic, cellular and coarse-grained structures are formed, which adversely affects the alloys mechanical and physical properties, as well as their processing parameters. For example, the inhomogeneity in the phase distribution in solders and the formation of large inclusions of the third component influence the melting temperature of the alloy [13].

At the ultrarapid liquid quenching process, the cooling rate of the liquid phase can be higher than $10^{5} \mathrm{~K} / \mathrm{s}$. The melt reaches a deep supercooling state before the beginning of solidification, and the solidification occurs with a high speed of movement at the interface between the melt and solid phases.

This leads to the formation of a structure which can not be obtained by using traditional fabrication technologies or by employing heat treatment. The use of ultrarapid cooling rate of the liquid phase (more than $10^{5} \mathrm{~K} / \mathrm{s}$ ) leads to the formation of a fine-grained structure, the formation of supersaturated solid solutions and also amorphization [14-16].

In addition, high-speed solidification is one of the energy-saving technologies that allows to lower the cost of solders [14]. The ultrarapid quenching enables obtaining solder in the shape of foils, which is convenient to use for certain types of soldering, for example, in automated processes. The foils obtained by the ultrarapid quenching are expected to have a more homogeneous structure with dispersed precipitates of phases and grains, which increases the quality of the material [17]. There is a very limited amount of studies available on solders obtained by the ultrarapid liquid quenching, and these are focused on high-temperature soldering alloys $[18,19]$. Hence, it is important to fabricate and study the microstructure of ultrarapidly quenched eutectic foils of zinc-doped indium-tin system in order to evaluate their potential for high-performance lowtemperature solders, their suitability for mass production and their use in the automation of the soldering process.

\section{Experimental procedure}

The ternary alloy with the composition of $\mathrm{Sn}$ (46.5 at.\%)-In (50.7 at.\%)-Zn (2.8 at.\%) (hereinafter referred to as $\mathrm{Sn} 46.5 \mathrm{In} 50.7 \mathrm{Zn} 2.8$ ) was fabricated by a 
conventional melting route from bulk tin, indium and zinc of a $4 \mathrm{~N}$ purity. A mass of about $0.2 \mathrm{~g}$ was cut off from the inner of the ingots and melted into a quartz tube at a temperature of $533-553 \mathrm{~K}$, called hereafter quenching temperature. The melted material was then quenched on the polished section of a rotating 20 -cm-diameter copper cylinder. The rotation speed of the cylinder was 25 rounds/s.

The quenched material was obtained in the shape of foils with a thickness of 30-70 $\mu \mathrm{m}$, a width of about $10 \mathrm{~mm}$ and a length of about $10 \mathrm{~cm}$. According to calculations $[15,16]$, the cooling rate was at least in the order of $10^{5} \mathrm{~K} / \mathrm{s}$ which corresponds to the ultrarapid quenching rate range.

The crystallographic structure was studied using a diffractometer (DRON-4 with a Copper anticathode). The foils texture was determined using the "inverse" pole figures. The polar densities, $\mathrm{P}_{\mathrm{hkl}}$, of the diffraction lines were calculated by the Harris method [20].

The foils microstructure was observed using a LEO 1455VP scanning electron microscope (SEM) (Karl Zeiss). X-ray spectral microanalysis was performed using an energy-dispersive spectrometer Aztec Energy Advanced X-Max 80.

The phase composition and the grain structure of the foils were studied by electron back-scattered diffraction (EBSD) method using the diffraction attachment of the phase analysis of HKL EBSD Premium System Channel 5. The phase and the orientation measurements rely on analyzing the EBSP patterns generated in the SEM from a polycrystalline sample. The crystal orientations and grain patterns are determined at each scan point (the scanning step is set depending on the magnification) for the phases present in the foil. EBSD allows determining the orientation of the crystal at each point of scanning with an accuracy of $2^{\circ}$, which makes it possible to detect high-angle $\left(>10^{\circ}\right)$ and small-angle (from $2^{\circ}$ to $\left.10^{\circ}\right)$ grain boundaries.

The foil microstructure parameters and the grain structure were determined by the random linear intercept method [21, 22]. The following parameters were determined for foils straight after fabrication and aged at room temperature, exposed to air for $150 \mathrm{~h}$ :

- the number of inclusions of zinc per unit area, n;

- the mean value of the chord lengths at sections of zinc inclusions, $\mathrm{dZn}, \mu \mathrm{m}$;
- the specific surface area of zinc interphase boundaries with eutectic phases Sn-In, SZn-inter, $\mu \mathrm{m}-1$;

- the volume fraction of zinc, VZn

The lengths of the chords of the random linear intercept were determined at the grain cross sections of each of the phases constituting the eutectic, $d z$, as well as the specific surfaces of the large-angle $S_{\text {l-angl }}$ (angle of misorientation $\alpha>10^{\circ}$ ), and the small-angle $\mathrm{S}_{\text {s-angl }}\left(2^{\circ}<\alpha<10^{\circ}\right)$ of grain boundaries of each eutectic phase.

The interphase and grain boundaries specific surfaces $\left(S_{Z n-i n t e r}, S_{\text {l-angl}}, S_{S-a n g l}\right)$ represent the total boundary area (S) per unit volume.

In the method of random linear intercept, $S$ was determined from the number of trace points of a given surface by units of secant length $(\mathrm{m})$ by the formula $S=2 \mathrm{~m}$. The relative error in determining the microstructure parameters did not exceed $10 \%$.

\section{Results and discussion}

The X-ray diffraction analysis of the ultrarapid quenched alloys revealed that the foils consisted of $\beta$ phase, $\gamma$-phase and inclusions of zinc by showing the presence of diffraction reflections of the $\beta$ phase $\left(\mathrm{In}_{3} \mathrm{Sn}\right)\left(002,200,202\right.$, etc.), of the $\gamma$ phase $\left(\mathrm{InSn}_{4}\right)$ $(0001,10 \overline{1} 0,10 \overline{1} \overline{2}$, etc.) and of zinc $(0002,10 \overline{1} \overline{2}, 10 \overline{1} 0$, etc.)

The elementary cell parameters for these phases were calculated and resulted to be: $\beta$-phase: $a=0.4855 \mathrm{~nm}, c=0.4410 \mathrm{~nm} ; \gamma$-phase: $a=0.3221 \mathrm{~nm}$, $c=0.2998 \mathrm{~nm} ; \mathrm{Zn}: a=0.2665 \mathrm{~nm}, c=0.44947 \mathrm{~nm}$.

The foils phase composition was confirmed by $\mathrm{X}$-ray spectral microanalysis. Figure 1 shows the In, $\mathrm{Sn}$ and $\mathrm{Zn}$ distribution obtained by scanning the surface with an electron beam along the line $\mathrm{L}-\mathrm{L}^{1}$. The areas with the maximum indium concentrations belong to the $\beta$ phase, while those with the maximum tin concentrations correspond to the $\gamma$-phase. The maxima in the distribution of zinc correspond to dark particles whose size does not exceed $1 \mu \mathrm{m}$. Hence, taking into account the X-ray diffraction results, it can be concluded that the dark inclusions correspond to the zinc phase.

A SEM image of the microstructure of the Sn46.5In50.7Zn2.8 foils is shown in Fig. 2 at different times after fabrication. The dark areas on the gray background indicate inclusions of zinc. 
Figure 1 Distribution of In, $\mathrm{Sn}$ and $\mathrm{Zn}$ at the foil surface along the $\mathrm{L}-\mathrm{L}^{\mathrm{I}}$ line

(a microstructure,

b concentration distribution).

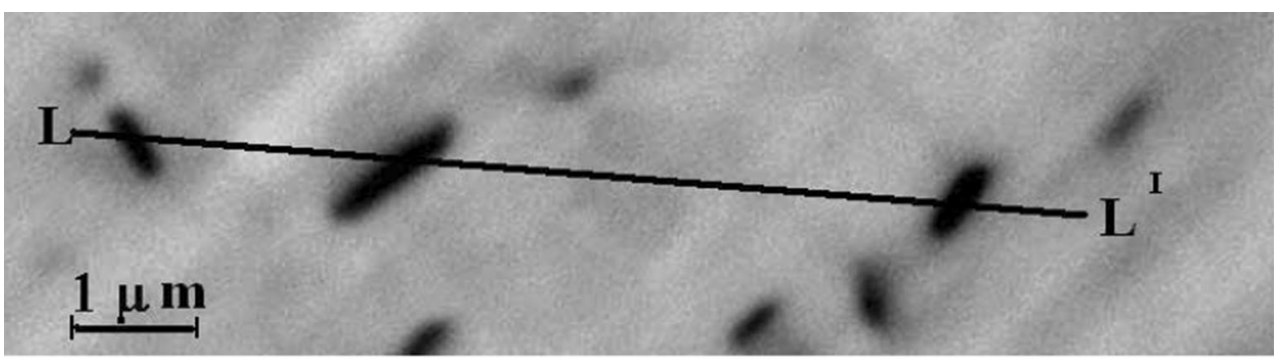

(a)

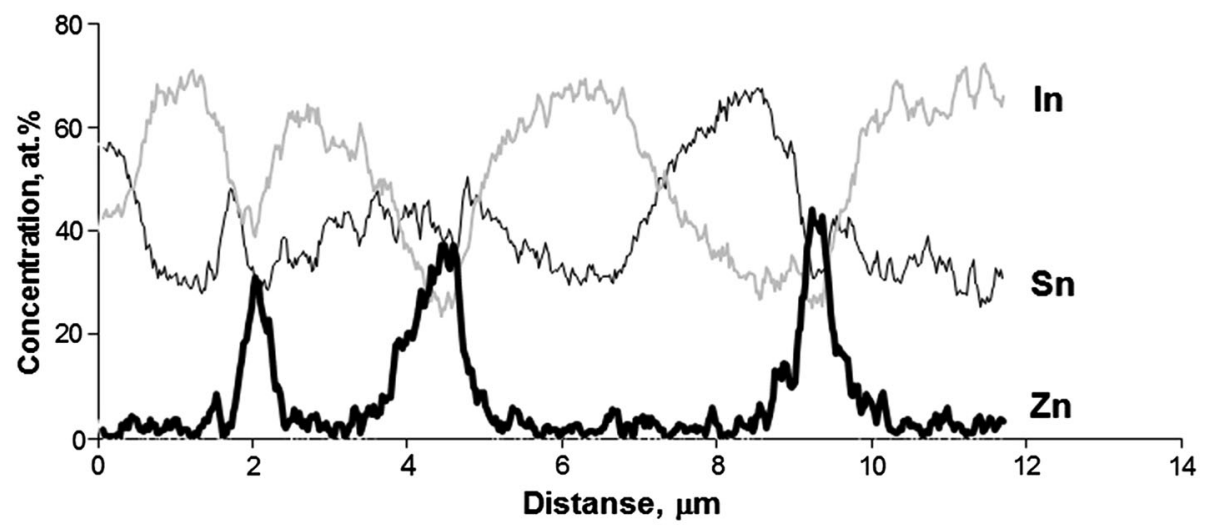

(b)
Shortly after manufacturing, zinc is precipitated as separate inclusions having an elongated shape. The non-equiaxial form of inclusions can be explained by anisotropy of the crystal lattice of zinc.

With further exposure at room temperature, zinc particles are enlarged due to the coalescence process. The microstructural parameters at 5 and $150 \mathrm{~h}$ after fabrication are presented in Table 1 and Fig. 3.

The volume fraction of zinc $V_{Z n}$ and the average length of chords $d_{Z n}$ of random secants located on sections of zinc particles increase for increasing exposure time at room temperature. However, the density of particles situated on the foil surface $n$ (number of particles per unit surface area) decreased by $30 \%$ with exposure time at room temperature. The decrease in particle density is associated with the processes of coalescence, the driving mechanisms of which is the decrease in the surface energy of the interphase boundaries.

Figure 3 shows histograms of the distribution of the mean length of the chord $d_{Z n}$ grouped by size after 5 and $150 \mathrm{~h}$ of foils exposure to air at room temperature. With time, the proportion of chords that fall in small dimensional groups decreases, and the proportion of chords that fall in large dimensional groups increases.
The specific surface area $\mathrm{S}_{\mathrm{Zn} \text {-inter }}$ of the interphase boundary of zinc particles with an eutectic consisting of $\beta$ - and $\gamma$-phases is independent of the exposure time at room temperature. This is due to the fact that the stability of the specific surface area $S_{Z n-i n t e r}$ of the interphase boundary of zinc particles with eutectics is caused by two processes occurring in the foils that take place simultaneously, i.e., an increase in the volume fraction of zinc, which leads to an increase in the specific surface and the coalescence processes that leads to its decrease. The microstructural changes in the ultrarapid liquid quenched foils take place thanks to the fact that their crystallization occurs with the formation of the supersaturated solid solutions and to the diffusion processes happening at room temperature in the alloys with low melting point.

An image of the grain structure of the $\beta$ - and $\gamma$ phases of the $\operatorname{Sn} 46.5 \operatorname{In} 50.7 \mathrm{Zn} 2.8$ alloy is shown in Fig. 4. The large-angled grain boundaries $\left(\alpha>10^{\circ}\right)$ and the small-angled boundaries $\left(2<\alpha<10^{\circ}\right)$ are shown with the black bold lines and with the thin black lines, respectively. The grains with various shapes of micron sizes have been observed.

The lengths of the chords of random linear intercept existing at the grain sections $\mathrm{d}_{\mathrm{z}}$ as well as the specific surfaces of the large-angle $S_{1-a n g l}$ and the 


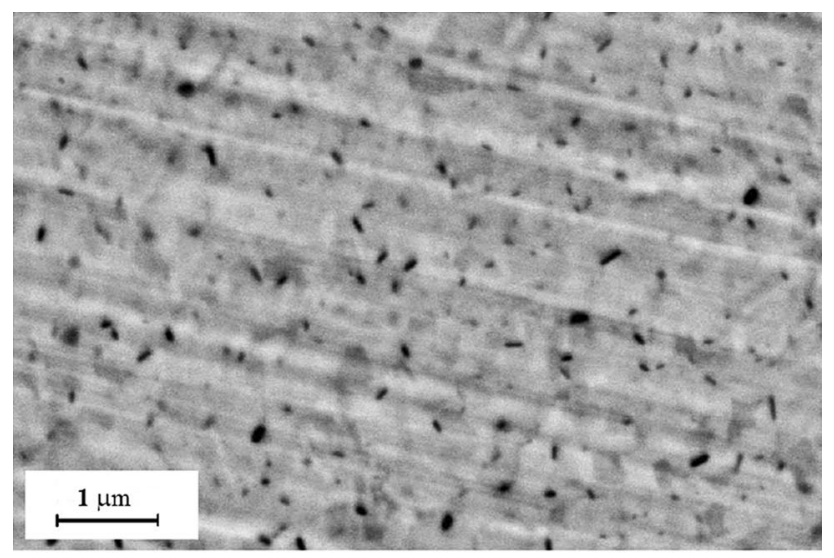

(a)

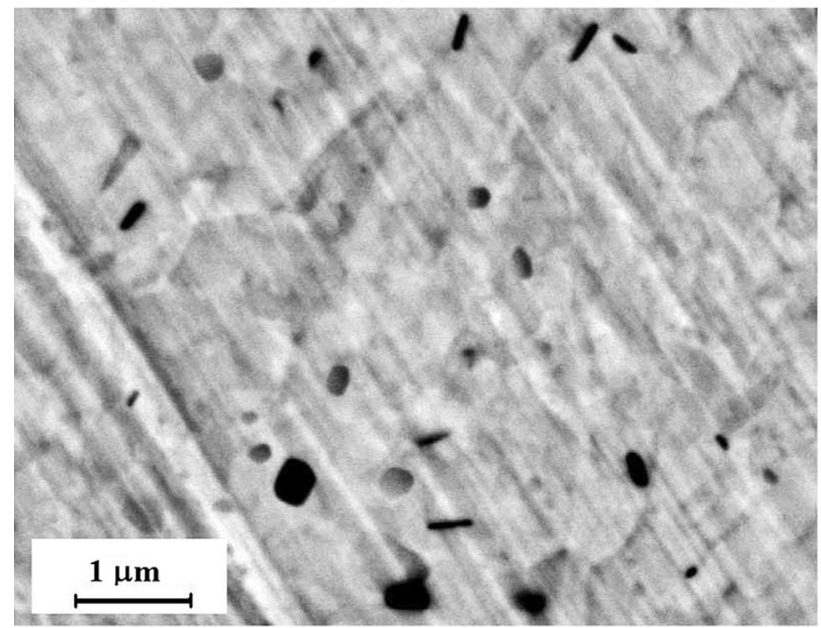

(b)

Figure 2 Microstructure of the Sn46.5 In50.7 Zn2.8 foils recorded $\mathbf{a} 5 \mathrm{~h}$ and $\mathbf{b} 150 \mathrm{~h}$ after being fabricated.

Table 1 Parameters of microstructure of Sn46.5 In50.7 Zn2.8 foils

\begin{tabular}{lll}
\hline Microstructural parameters & \multicolumn{2}{l}{ Exposure time (h) } \\
\cline { 2 - 3 } & 5 & 150 \\
\hline$V_{\mathrm{Zn}}$ & 0.011 & 0.021 \\
$d_{\mathrm{Zn}}(\mu \mathrm{m})$ & 0.24 & 0.46 \\
$S_{\mathrm{Zn}-\vartheta}\left(\mu \mathrm{m}^{-1}\right)$ & 0.19 & 0.18 \\
$n\left(\mu \mathrm{m}^{-2}\right)$ & 0.098 & 0.062 \\
\hline
\end{tabular}

small-angle $S_{\text {s-angl }}$ grain boundaries of the eutectic phases have been determined. The parameters of the grain structure are shown in Table 2.

The values of $S_{\text {-angl }}$ for the $\beta$ - and for $\gamma$-phase were found to be $0.50 \mu \mathrm{m}^{-1}$ and $0.016 \mu \mathrm{m}^{-1}$, respectively. Typically, small-angle boundaries were observed in

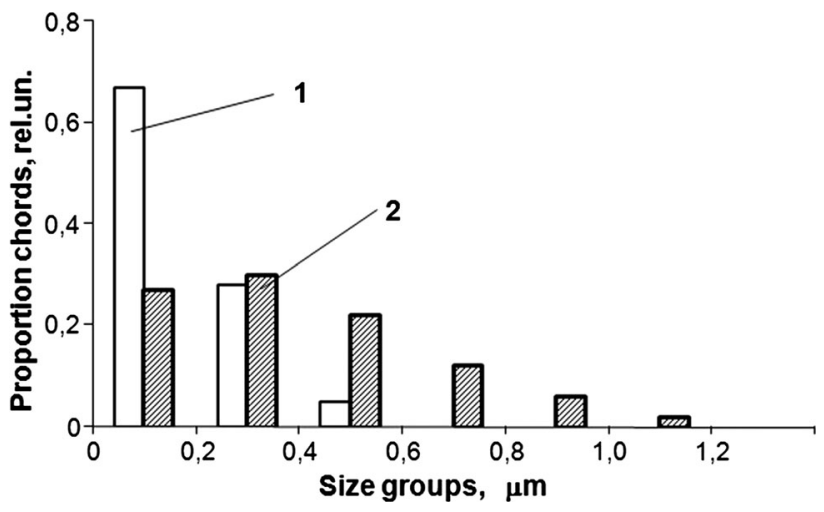

Figure 3 Histogram of distribution of chords of random linear intercept on sections of zinc after $5 \mathrm{~h} \mathrm{(1)} \mathrm{and} \mathrm{after} 150 \mathrm{~h}$ (2) aging at room temperature and exposed to air after the foils were manufactured.

large grains (up to 20 microns). The values for $S_{\mathrm{s} \text {-angl }}$ in the $\beta$ - and $\gamma$-phases were determined as $0.07 \mu \mathrm{m}^{-1}$ and $=0.007 \mu \mathrm{m}^{-1}$, respectively.

The histogram (Fig. 5) shows the distribution of chord lengths of linear intercept on grains sections according to the size groups. The largest proportion of chords was found in the group with the size of the chords no larger than 1.4 microns.

The average chord length at the grain sections of the $\beta$ - and $\gamma$-phases were found as $d_{\beta}=3.2 \mu \mathrm{m}$ and $d_{\gamma}=2.1 \mu \mathrm{m}$, respectively, which indicates the formation of the microcrystalline structure. The reason for the formation of the small grains is an increase in the rate of nucleation with a simultaneous decrease in the rate of the grains growth, which occurs in the case of a deep undercoolings, which occurs at ultrarapid quenching [12].

The crystal lattices of the $\beta$ - and $\gamma$-phases were found to be tetragonal and hexagonal, both of which are very anisotropic in nature. Therefore, in the presence of a significant predominant orientation of grains (textures), polycrystalline foils can be characterized by anisotropy of properties. This is why, the study of the texture of foils is of particular importance. Table 3 shows the values of the pole densities $P$ of the diffraction lines for both phases.

The greatest pole density is characterized by the diffraction lines of 200 and 0002 for $\beta$ phase and $\gamma$ phase, respectively. Thus, the ultrarapid liquid quenching process of the Sn46.5In50.7Zn2.8 alloy leads to the formation of the (100) texture in the $\beta$ phase and the (0001) texture in the $\gamma$-phase. Similar textures were observed earlier and separately in the 


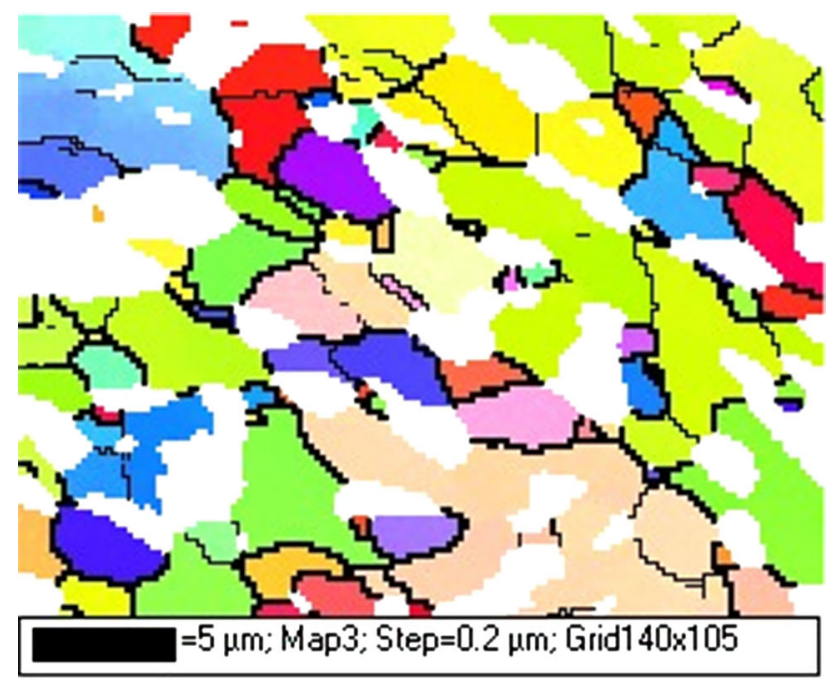

(a)

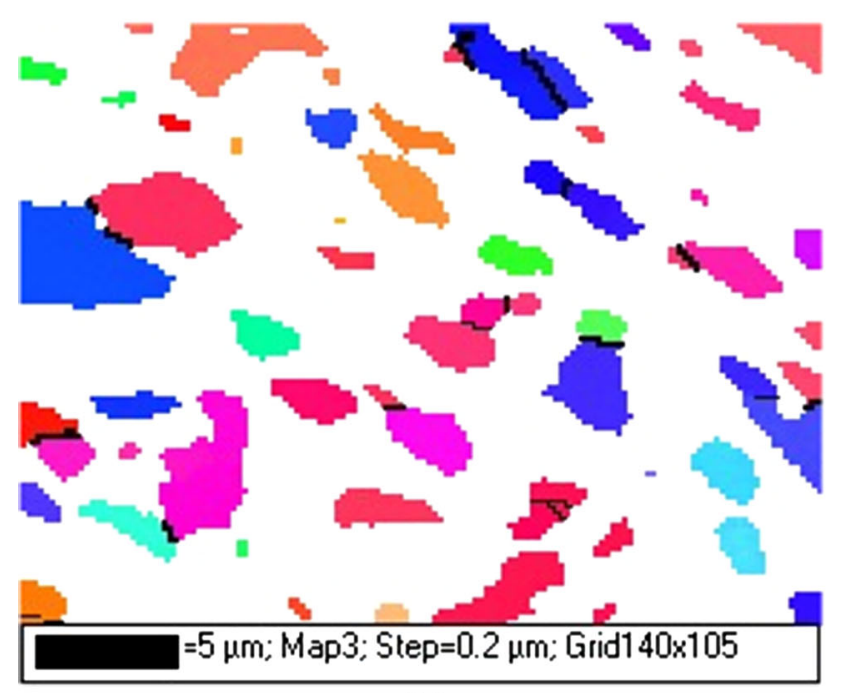

(b)

Figure 4 Grain structure of the $\operatorname{Sn} 46,5 \operatorname{In} 50,7 \mathrm{Zn} 2,8$ foil: a $\beta$ phase, $\mathbf{b} \gamma$-phase.

Table 2 Parameters of the grain structure of the $\beta$ - and $\gamma$-phases

Parameters of the grain structure

Phases

\begin{tabular}{lll}
\cline { 2 - 3 } & $\beta$ & $\gamma$ \\
\hline$d_{\mathrm{z}}(\mu \mathrm{m})$ & 3.2 & 2.1 \\
$\mathrm{~S}_{\text {l-angl }}\left(\mu \mathrm{m}^{-1}\right)$ & 0.50 & 0.016 \\
$\mathrm{~S}_{\mathrm{s} \text {-angl }}\left(\mu \mathrm{m}^{-1}\right)$ & 0.07 & 0.007 \\
\hline
\end{tabular}

$\mathrm{In}_{3} \mathrm{Sn}$ ( $\beta$-phase) and $\operatorname{InSn}_{4}(\gamma$-phase), obtained by highspeed solidification $[23,24]$.

This texture formation in the phases can be explained by the theory of irreversible processes

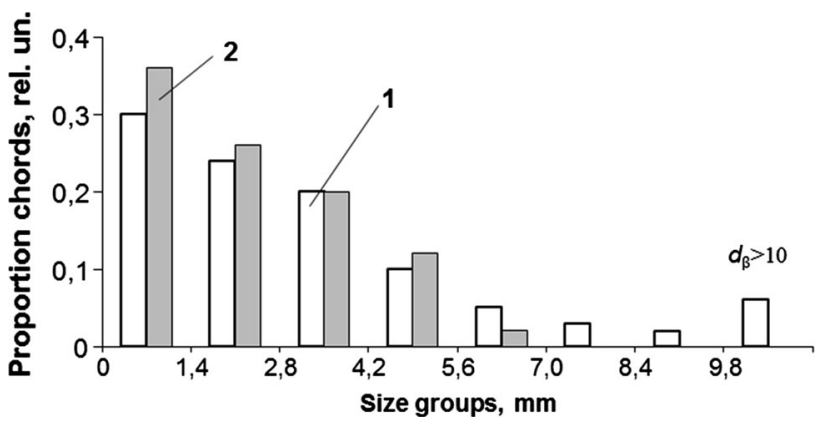

Figure 5 Histogram of distribution of chords of random linear intercept on grains sections of the $\beta$-phase (1) and $\gamma$-phase (2).

Table 3 Values of the polar density of the diffraction lines of the $\beta$ and $\gamma$ phases

\begin{tabular}{lllll}
\hline$\beta$-phase & & & $\gamma$-phase \\
\cline { 1 - 1 } \cline { 5 - 5 } Diffraction lines & $P$ & & Diffraction lines & $P$ \\
\hline 002 & 0.1 & & $10 \overline{1} \overline{1}$ & 0.3 \\
102 & 0.0 & & $1 \overline{\overline{2}} 0$ & 1.2 \\
200 & 4.9 & & 0002 & 3.4 \\
201 & 0.5 & & $11 \overline{2} \overline{1}$ & 0.2 \\
202 & 0.4 & & $20 \overline{2} 0$ & 1.7 \\
220 & 0.2 & & $10 \overline{1} \overline{2}$ & 0.3 \\
- & - & & $20 \overline{2} \overline{1}$ & 0.1 \\
\hline
\end{tabular}

$[25,26]$. Due to a significant supercooling, the melt is in a state with a significant excess of enthalpy. According to the principle of the maximum speed of dissipation forces, investigated by G. Ziegler [25], the transition of the supercooled melt to the equilibrium state occurs in such a way that the rate of enthalpy decrease in the alloy during the crystallization process is maximal.

Therefore, the direction of crystallization, coinciding with the direction of the heat sink, must be perpendicular to the most densely packed planes that have the greatest interplanar distance. In the work by Li and Szpunar [26], the energy barriers for moving the liquid-crystal interphase boundary for different crystallographic planes in metals with a face-centered cubic lattice were calculated. According to these calculations, the largest value of the energy barrier was observed in the case of coincidence of the interphase boundary with crystallographic planes $\{111\}$ that have the greatest interplanar distance (these planes are close-packed). 
This principle has been demonstrated in studies of the texture in metals with a face-centered crystal lattice [27-29]. The texture formation was also observed earlier in the ultrarapidly quenched foils of aluminum, lead, tin and zinc.

\section{Conclusion}

The foils of Sn46.5In50.7Zn2.8 alloy obtained by rapid solidification consist of zinc supersaturated solid solutions based on $\beta$-phase (In3Sn) and $\gamma$-phase (InSn4) and dispersed zinc particles formed as a result of the decomposition of the supersaturated solid solutions, the size of which does not exceed $1 \mu \mathrm{m}$.

The solidification occurs during deep supercooling of the melt at which high nucleation and low grain growth rate leads to the formation of a microcrystalline structure of foils with an average grain size of $3.2 \mu \mathrm{m}$ and $2.1 \mu \mathrm{m}$, as well as textures (100) and (0001) in the $\beta$-phase and $\gamma$-phase, respectively.

Traditionally, grains with microsize dimensions are considered as ultrafine grain structures for ultrarapid liquid quenching technology. In addition the grains with the submicron size could also be observed.

Open Access This article is distributed under the terms of the Creative Commons Attribution 4.0 International License (http://creativecommons.org/ licenses/by/4.0/), which permits unrestricted use, distribution, and reproduction in any medium, provided you give appropriate credit to the original author(s) and the source, provide a link to the Creative Commons license, and indicate if changes were made.

\section{References}

[1] Zeng K et al (2002) Six cases of reliability study of $\mathrm{Pb}$ free solder joints in electronic packaging electronic. Mater Sci Eng 38:55-105

[2] Tu KN et al (2003) Physics and materials challenges for lead-free solders. J Appl Phys 93:1335-1353

[3] Nadia A (2009) The fabrication of composite solder by addition of copper nano powder into $\mathrm{Sn}-3.5 \mathrm{Ag}$ solder. In:
Proceedings of the international conference on electronic packaging technology \& high density packaging (ICEPTHDP'09), pp 607-610

[4] Bath J ed (2007) Lead-free soldering, Springer, Chapter 2: fundamental properties of $\mathrm{Pb}$-free solder alloys

[5] O’Neill T (2018) Life after SAC http://www.aimsolder.com/ Accessed. Accessed May 152018

[6] Chen ZG, Shi YW, Xia ZD, Yan YF (2002) Study on the microstructure of a novel lead-free solder alloy $\mathrm{SnAgCu}-\mathrm{RE}$ and its soldered joints. J Electron Mater 31(10):1122-1128

[7] Lii Q, Leii Y, Lin J, Yangi S (2015) Design and properties of $\mathrm{Sn}-\mathrm{Bi}$-In low-temperature solders. In: Proceedings of the 16 th international conference on electronic packaging technology, pp 497-500

[8] Hindler Michael, Guo Zhongnan, Mikula Adolf (2012) Lead-free solder alloys: thermodynamic properties of the $(\mathrm{Au}+\mathrm{Sb}+\mathrm{Sn})$ and the $(\mathrm{Au}+\mathrm{Sb})$ system. J Chem Thermodyn 55:102-109

[9] Maruya Y, Hata H, Shohji I, Koyama S (2017) Fabrication of high melting point joint using $\mathrm{Sn}-57 \mathrm{Bi}-1 \mathrm{Ag}$ low temperature lead-free solder and gold-plated electrode. In: ICEP proceedings, pp 551-554

[10] Anryushchenko M (2004) Lead-free soldering. Altern Alloys Electron Sci Technol Bus 5:47-49

[11] Al-Ganainy GS (2002) Creep characteristics of a new Pbfree soldering $\mathrm{Sn}-\mathrm{In}$ pewter. Phys Status Solidi 193(2):226-235

[12] Shen J, Wu CP, Li SZ (2012) Effects of rare earth additions on the microstructural evolution and microhardness of Sn30Bi0.5Cu and Sn35Bi1Ag solder alloys. J Mater Sci Mater Electron 23(1):156-163

[13] Song Jenn-Ming, Zong-Mou Wu (2006) Variable eutectic temperature caused by inhomogeneous solute distribution in Sn-Zn system. Scr Mater 54:1479-1483

[14] Vasiliev VA, Mitin BS, Pashkov IN, Serov MM, Skuridin AA, Lukin AA, Yakovlev VB (1998) Rapid solidification of melts (theory, technology and materials). SP Intermet Engineering, Moscow (in Russian)

[15] Miroshnichenko IS (1982) Hardening from the liquid state. Metallurgy, Moscow

[16] Shepelevich VG (2015) Rapidly solidified low-melting alloys. BSU, Minsk

[17] Pashkov IN, Pikinov MV, Tavolzhansky SA, Pashkov AI (2010) Developmen of production and use of solder alloys microcrystalline or amorphous structure. Metallurgist 6:43-45

[18] Pashkov N, Pikunov MV, Tavolzhanskii SA, Pashkov AI (2010) Development of processes for preparation and use of solder alloys in a dispersed state with a microcrystalline or amorphous structure. Metallurgist 54(5-6):358-361 
[19] Kalin BA, Fedotov VT, Seryukov ON et al (1996) Amorphous solder tape for high-temperature soldering. Experience of developing production technology and application. Svar Proizv 1:15-19

[20] Rusakov AA (1977) Radiography of metals. Atomizdat, Moscow

[21] Saltykov SA (1976) Stereometric metallography. Metallurgy, Moscow

[22] Vander GeorgeF (1884) Voort metallography, principles and practice. ASM International, Almere

[23] Jingjie W, Shepelevich VG (2010) Structure of the fasthardened $\beta$ phase of the In-Sn system. Bull Belarusian State Univ Ser 1(3):27-29

[24] Jingjie W, Shepelevich VG (2011) Structure and microhardness of the fast-cured $\gamma$-phase of the In-Sn system. Wang Jingjie Bull the Belarusian State Univ Ser 1:22-24
[25] Ziegler G (1966) Extremal principles of thermodynamics of irreversible processes in continuum mechanics. Mir, Moscow

[26] Li DY, Szpunar JA (1994) A possible pole for surface packing density in the formation of (111) texture in solidified FCC metals. J Mater Sci Lett 13:1521-1523

[27] Shepelevich VG, Sivtsova PA, Vasilevich EYu, Gutko ES (2005) Texture of rapidly solidified foils of aluminium and its alloys. J Alloys Compd 403:265-269

[28] Lozenko VV, Shepelevich VG (2006) Rapidlysolifified foils of binary alloys of zinc with cadmium, aluminum, tin and indium. Phys Chem Met Process 4:67-72

[29] Gusakova OV, Shepelevich VG (2012) Rapidlysolidified alloys of tin. Minsk PIVSH, Minsk 